\title{
AKED远A \\ O USO DO CONHECIMENTO NA SOCIEDADE
}

\author{
English title: THE USE OF KNOWLEDGE IN SOCIETY \\ doi>10.33726/akdpapers2447-7656v11a72021p98-110 \\ HAYEK, Friedrich August von'
}

\begin{abstract}
RESUMO: Hayek discute neste artigo que tipo de conhecimento deve ser utilizado nas Ciências Sociais, especialmente na Economia. Mostra que, no mundo real, o dito "conhecimento científico" falha na coordenação da atividade econômica e que o conhecimento "prático", ou das circunstâncias de tempo e espaço, é que é relevante nas decisões dos agentes econômicos.
\end{abstract}

PALAVRAS-CHAVE: Imperfeição do Conhecimento, Sociedade, Ciências Sociais, Sistema de Preços, Planejamento, Circunstâncias de Tempo e Espaço

ABSTRACT: Hayek discusses in this article what kind of knowledge should be used in Social Sciences, especially in Economics. It shows that, in the real world, the so-called "scientific knowledge" fails to coordinate economic activity and that "practical" knowledge, or the circumstances of time and space, is relevant in the decisions of economic agents.

KEYWORDS: Imperfection of Knowledge, Society, Social Sciences, Price System, Planning, Circumstances of Time and Space

\section{NOTA POST SCRIPTUM PARA ESTA EDIÇÃO}

O presente Artigo foi publicado originalmente com o título "The Use of Knowledge in Society", em setembro de 1945, na American Economic Review, v. 35, n. 4, p. 519-530. Foi, também, reeditado como Capítulo de Livro, disponível em: F. A. von HAYEK. Individualism and Economic Order. Chicago: University Chicago Press, 1948. Neste caso, foi traduzido do inglês para o português, por Phillippe A. Gebara Tavares.

$\mathrm{Na}$ presente edição do Paper, a Equipe Editorial da Revista AKEDIA recuperou o texto, já em português, de uma publicação feita pelo Instituto Mises Brasil, intitulada Revista Interdisciplinar de Filosofia, Direito e Economia, v. 1, n. 1, jan-jul. de 2013, p. 153-162. Nesta condição, fez-se nova revisão ortográfica (ajustando a escrita ao novo acordo ortográfico brasileiro). Realizou-se, também, um copidesque geral do Artigo, para aprimoramentos de formatação, de linguagem científica, gramatical e de normas da ABNT, com inclusão de notas editoriais de esclarecimento ao leitor. Fezse a imposição de número $\mathrm{DOI}$, conferindo ao texto uma URL persistente, garantindo aos pesquisadores 0 acesso digital permanente à obra, por meio das bases indexadoras nacionais $\mathrm{e}$ internacionais. Na medida do possível, a editoração manteve a tradução original de Gebara Tavares.

\footnotetext{
${ }^{1}$ Doutor em Direito e Ciência Política, estudou Filosofia, Psicologia e Economia. Friedrich August von Hayek (1899-1992) nasceu austríaco, posteriormente foi naturalizado britânico. Contudo, é considerado um dos maiores representantes da "Escola Austríaca" de pensamento econômico. Nos idos de 1920, juntamente com Ludwig von Mises (1881-1973), fundou e dirigiu o "Austrian Institute for Business Cycle Research". Sua grande obra é a intitulada "O Caminho da Servidão" (Instituto Mises Brasil, 2010). Foi Nobel de Economia, em função de sua Teoria da Moeda e Flutuações Econômicas.
} 
Qual é o problema que buscamos resolver quando tentamos construir uma ordem econômica racional? Partindo de alguns pressupostos amplamente aceitos, a resposta é bastante simples.

Se detivéssemos todas as informações relevantes, se pudéssemos tomar como ponto de partida um sistema de preferências estabelecido, e se tivéssemos completo conhecimento dos meios disponíveis, o resto do problema seria simplesmente uma questão de lógica. Ou seja, a resposta para a pergunta por qual é o melhor uso dos meios disponíveis está implícita em nossos pressupostos.

As condições que devem ser satisfeitas para a solução desse problema ideal foram completamente analisadas e podem ser mais bem expostas em um modelo matemático: sucintamente, diríamos que as taxas marginais de substituição entre quaisquer dois bens ou fatores devem ser as mesmas, independentemente dos seus diferentes usos.

Este, no entanto, decididamente não é o problema econômico que a sociedade enfrenta. E o cálculo econômico que desenvolvemos para resolver esse problema lógico, embora seja um importante passo na direção da solução do problema econômico da sociedade, não oferece ainda uma resposta para ele. O motivo disto é que os "dados" totais da sociedade a partir dos quais são feitos os cálculos econômicos nunca são dispostos a uma única mente para que pudesse analisar as suas implicações - e nunca serão.

O caráter peculiar do problema de uma ordem econômica racional se caracteriza justamente pelo fato de que o conhecimento das circunstâncias sob as quais temos de agir nunca existe de forma concentrada e integrada, mas apenas como pedaços dispersos de conhecimento incompleto e frequentemente contraditório, distribuídos por diversos indivíduos independentes.

O contexto econômico da sociedade, portanto, não é meramente um problema de como alocar "determinados" recursos - se por "determinados" entendermos algo que esteja disponível a uma única mente que possa deliberadamente resolver a questão com base nessas informações.

Em vez disso, o assunto se concentra em como garantir que qualquer membro da sociedade faça o melhor uso dos recursos conhecidos, para fins cuja importância relativa apenas estes indivíduos conhecem. Ou, colocando sucintamente, o problema incide sobre a utilização de um conhecimento que não está disponível a ninguém em sua totalidade.

O caráter fundamental desse pressuposto tem sido, infelizmente, obscurecido, e não iluminado, por muitos dos recentes refinamentos na Teoria econômica e, em particular, pelos usos variados da Matemática. E, embora o problema de que eu queira tratar primordialmente nesse artigo seja o da organização de uma economia racional, para seguir esse caminho precisarei de repetidamente chamar atenção para as ligações íntimas que esse tema possui com certas questões metodológicas.

Muitos dos argumentos que pretendo apresentar são, de fato, conclusões alcançadas por meio de diferentes caminhos de raciocínio que inesperadamente convergiram. Mas, do modo como eu hoje entendo essas questões, essa convergência não é uma coincidência. Parece-me que muitas 


\section{AKEDIA}

das divergências que surgem, tanto no campo da teoria econômica quanto no da política econômica, possuem uma origem comum em uma má compreensão da natureza do diagnóstico econômico da sociedade. Essa má compreensão, por sua vez, se deve a uma aplicação indevida de hábitos mentais desenvolvidos para lidar com problemas da natureza aos fenômenos sociais.

\section{PARTE II}

$\mathrm{Na}$ linguagem comum, definimos a palavra "planejar" como sendo o conjunto das decisões inter-relacionadas e relativas à alocação dos nossos recursos disponíveis. Toda atividade econômica, nesse sentido, é um planejamento e, em qualquer sociedade em que várias pessoas colaborem e, independentemente de quem o faça planejamento, terá de basear-se em certos conhecimentos.

Esses conhecimentos não estarão disponíveis em primeira instância para o planejador, mas, antes, para alguém que deverá retransmiti-los a tal mentor. Os vários modos pelos quais o conhecimento chega às pessoas que o utilizam para elaborar seus planos é um problema crucial para qualquer teoria que almeje explicar o processo de mercado. Por sua vez, o problema de qual é o melhor modo de utilizar o conhecimento que está inicialmente disperso entre várias pessoas independentes é pelo menos um dos principais problemas para a política econômica - ou para qualquer tentativa de conceber um sistema econômico eficiente.

A resposta para essa pergunta está intimamente relacionada com outra questão que emerge aqui, que é a de se conhecer "quem está planejando?".

Toda a divergência sobre "planejamento econômico", portanto, parte dessa questão. Não está em discussão se se deve planejar ou não, mas, sim, se o planejamento deve ser feito de forma centralizada, por uma autoridade única para todo o sistema econômico, ou se ele deve ser dividido entre vários indivíduos.

No sentido específico, em que o termo é utilizado nas controvérsias contemporâneas, "planejamento" implica, necessariamente, um conceito de "planejamento central" - isto é, direcionar todo o sistema econômico de acordo com um projeto unificado.

A competição, por outro lado, significa uma descentralização do planejamento, que será realizado por muitas pessoas independentes. $O$ caminho do meio entre essas duas posições - muito falado, mas pouco apreciado quando visto em prática - é a delegação do planejamento para certas indústrias organizadas, isto é, a instituição de monopólios.

A questão de qual desses sistemas será mais eficiente depende principalmente da questão de qual deles podemos esperar um uso mais completo do conhecimento existente. $E$ isto, por sua vez, depende de se nós temos uma probabilidade maior de conseguir colocar todo o conhecimento que está disperso entre vários indivíduos à disposição de uma autoridade central, ou de dar aos indivíduos um conhecimento adicional suficiente para que eles se tornem capazes de integrar os seus planos aos dos outros. 


\section{PARTE III}

Ficará imediatamente evidente que, neste ponto, a resposta será tanto diferente quanto forem os diversos tipos de conhecimento, e a resposta para a nossa pergunta irá, consequentemente, voltar-se para a importância relativa destes distintos níveis de conhecimento. Isto inclui a ideia de se conhecerem aqueles conteúdos que mais provavelmente estarão à disposição de indivíduos particulares, e aqueles com os quais teríamos mais certeza de encontrar na posse de um órgão constituído por especialistas bem escolhidos.

Se hoje em dia é tão amplamente aceito que a segunda opção é preferível, isto ocorre porque um tipo de conhecimento - o conhecimento científico - ocupa, nos dias de hoje, um lugar tão proeminente na imaginação pública que chegamos mesmo a esquecer de que esse não é o único tipo de conhecimento relevante.

Pode-se admitir que, em relação ao conhecimento científico, um órgão com um punhado de especialistas bem escolhidos seja a melhor opção para melhor dominar o conhecimento disponível - embora saibamos que isso, obviamente, se constitua meramente no ato de trocar um problema por outro: 0 problema de como escolher esses especialistas.

O que desejo frisar é que, mesmo presumindo que esse problema pudesse ser imediatamente resolvido, ele seria apenas parte de um problema maior. Assim é que hoje, é quase uma heresia sugerir que o conhecimento científico não corresponde à totalidade do conhecimento.

Mas, apenas com um pouco de reflexão se irá mostrar que, sem sombra de dúvida, existe um corpo importantíssimo de conhecimento desorganizado que não pode ser chamado de científico, entendendo por "científico" como o domínio de certas regras gerais, tais como o conhecimento de certas circunstâncias particulares de tempo e lugar.

É em relação a isso que praticamente todo indivíduo tem alguma vantagem comparativa em relação a todos os outros, pois ele possui informações únicas sobre que tipos de usos benéficos podem ser feitos com certos recursos, usos estes que só acontecerão se a decisão de como utilizálos for deixada nas mãos desse indivíduo ou for tomada com sua cooperação ativa.

Basta apenas nos lembrarmos do quanto precisamos aprender em qualquer profissão depois de termos completado nossa formação teórica, e o quão grande é a parte da nossa vida profissional em que passamos aprendendo habilidades específicas, e o quão valioso, em todas as circunstâncias da vida, é o conhecimento das pessoas, das condições locais e de certas circunstâncias especiais.

Conhecer e saber operar uma máquina que não estava sendo adequadamente explorada, ou explorar a habilidade de alguém que poderia ser mais bem aproveitado, ou estar consciente de um excedente de reservas que pode ser usado durante uma interrupção temporária do fornecimento é tão útil socialmente quanto o conhecimento das melhores técnicas alternativas.

O transportador que ganha sua vida descobrindo como melhor aproveitar seu espaço de carga que ficaria vazio, o agente imobiliário cujo conhecimento consiste quase que exclusivamente em encontrar oportunidades temporárias, ou o indivíduo que faz arbitragem, que lucra a partir das 
diferenças locais entre os preços de certos bens - todos eles realizam trabalhos eminentemente úteis que são baseados em um conhecimento especial das circunstâncias de um momento fugidio, desconhecido por outros.

É curioso que nos dias de hoje esse tipo de conhecimento seja amplamente menosprezado, e que as pessoas que fazem uso dele para alcançarem privilégios sobre pessoas com melhor preparo teórico ou técnico sejam vistas quase como se estivessem fazendo algo desonrado. Mas, embora conquistar privilégios usando um conhecimento superior quanto às condições de comunicação e transporte seja visto como algo quase desonesto, a verdade é que, para a sociedade, é quase tão importante fazer o melhor uso possível dessas oportunidades quanto das últimas descobertas científicas.

Esse preconceito tem uma influência considerável sobre o fato de as pessoas costumarem adotar uma atitude mais desfavorável em relação ao comércio do que em relação às atividades produtivas. Mesmos os economistas que se creem totalmente imunes às rasas falácias materialistas do passado, constantemente cometem os mesmos erros em relação às atividades relacionadas à aquisição de conhecimento prático - e o motivo disso parece ser que, segundo 0 modo como eles veem o mundo, esse tipo de conhecimento já deveria estar "dado" em vez de ser algo que precise ser buscado.

A ideia mais comum na atualidade parece ser a de que todo conhecimento desse tipo deveria estar constantemente disponível para todo mundo e, como isso não ocorre, critica-se a ordem econômica atual por ser supostamente irracional. Essa concepção ignora o fato de que o método de tornar esse conhecimento amplamente disponível é precisamente o problema que precisamos resolver.

\section{PARTE IV}

Se, hoje em dia, está na moda minimizar a importância do conhecimento das circunstâncias particulares de tempo e espaço, isso se deve em grande medida a pouca importância dada à questão da incerteza em si mesma. De fato, parte dos pressupostos (que geralmente estão apenas implícitos) adotados pelos "planejadores" difere dos seus oponentes tanto em relação à capacidade de mudanças imprevistas causarem alterações substanciais nos planos de produção quanto em relação à frequência com que isso ocorre.

Evidentemente, se fosse possível fazer previamente planos econômicos detalhados para períodos significativamente longos, e depois segui-los à risca, de modo que nenhuma outra decisão econômica importante fosse necessária, a tarefa de elaborar um planejamento completo para toda a atividade econômica não seria algo tão inatingível.

Talvez valha a pena frisar que os problemas econômicos surgem sempre e exclusivamente em decorrência de variáveis não previsíveis. Enquanto as coisas continuam exatamente como estavam antes - ou ao menos quando elas prosseguem de acordo com o que se esperava delas então não surgirão novos problemas que exijam soluções, não havendo, portanto, necessidade de que se elabore um novo planejamento.

A crença de que a mudança - ou ao menos os pequenos ajustes cotidianos - se tornou menos importante nos tempos modernos parte do princípio de que a contenção dos problemas econômicos também se tornou 
menos importante. Por esse motivo, as pessoas que costumam menosprezar a importância da incerteza são as mesmas que argumentam que as questões econômicas já não são tão importantes quanto o conhecimento tecnológico.

Será verdade que, graças ao sofisticado aparato da indústria moderna, só é preciso tomar decisões econômicas em intervalos longos; como na hora de decidir se uma nova fábrica deve ser construída, ou um novo procedimento deve ser introduzido? É verdade que, uma vez que uma fábrica tenha sido construída, o resto é mais ou menos mecânico, determinado por suas características, deixando pouco a ser mudado para adaptar-se às eternas flutuações de cada momento?

A experiência prática dos empreendedores, até onde eu a conheço, não sustenta essa crença amplamente aceita. Pelo menos nas áreas que são competitivas - e apenas essas áreas servem de modelo para essa questão a tarefa de impedir os custos de subir exige um luta constante, que absorve grande parte da energia do administrador.

É fácil para um administrador ineficiente gastar as pequenas sobras de onde saem os lucros. É um lugar-comum da experiência empresarial que, com as mesmas condições técnicas, a mesma produção pode ser feita dentro de uma variedade enorme de custos - mas isso não é igualmente conhecido pelos que estudam apenas a Economia.

O próprio desejo - frequentemente declarado pelos produtores e engenheiros - de ser autorizado a fazer seus projetos sem considerações financeiras - é um testemunho eloquente do poder que esses fatores exercem sobre seu trabalho diário.

Um dos motivos para a crescente incapacidade dos economistas de atentarem para as constantes pequenas mudanças que compõem o todo da atividade econômica é provavelmente o fato de que eles estão cada vez mais preocupados com dados estatísticos, que passam uma imagem muito mais estável da Economia do que os pequenos movimentos diários.

No entanto, a relativa estabilidade dos grandes dados estatísticos não pode ser explicada - como os estatísticos frequentemente querem fazer crer - pelas "leis dos grandes números" ou pela mútua compensação de pequenas mudanças aleatórias. O número dos elementos com que eles lidam não é grande o suficiente para que essas forças acidentais produzam estabilidade.

O contínuo fluxo de bens e serviços é mantido por ajustes deliberados e constantes, por novas decisões tomadas diariamente à luz de circunstâncias que eram desconhecidas até o dia anterior, pela decisão de "B" de entrar em cena quando "A" deixa de executar o seu papel.

Mesmo a maior e mais mecânica das fábricas segue adiante em grande parte por causa de um ambiente que pode lhe prover todas as suas demandas inesperadas: novas telhas para seu telhado, papéis para seus documentos, e todos os mil e um tipos de equipamentos que não podem ser produzidos pela própria fábrica, mas que, para que ela continue a funcionar, precisam estar facilmente disponíveis no mercado.

Nesse instante, devo brevemente observar que o tipo de conhecimento de que tenho tratado é de um tipo que, por sua própria natureza, não pode ser transposto para dados estatísticos e que, por isso, não pode ser colocado à disposição de uma autoridade central que delibere a partir de levantamentos matemáticos. 


\section{AKED亚A}

As estatísticas que essa autoridade teria de utilizar surgiriam exatamente por meio das abstrações das pequenas diferenças entre as coisas, juntando como se fossem elementos de um só tipo itens com diferentes características de lugar, qualidade e outras características particulares, que seriam muito importantes para tomar uma decisão específica.

Consequentemente, um planejamento central baseado em informações estatísticas, por sua própria natureza, não pode levar em consideração diretamente as circunstâncias de tempo e lugar, precisando encontrar algum jeito de essas decisões serem deixadas para alguém que esteja no local.

\section{PARTE V}

Se pudermos convir que o problema econômico da sociedade é basicamente uma questão de se adaptar rapidamente às mudanças das circunstâncias particulares de tempo e lugar, parece ser evidente que, por consequência, as decisões fundamentais devem ser deixadas a cargo de pessoas que estejam familiarizadas com essas circunstâncias, que possam conhecer diretamente as mudanças relevantes e os recursos imediatamente disponíveis para lidar com elas. Não podemos esperar que esse problema seja resolvido por meio da transmissão de todo esse conhecimento para um diretório central que, depois de ter integrado todo esse saber, emita uma ordem.

Precisamos da descentralização porque apenas assim podemos garantir que o conhecimento das circunstâncias particulares de tempo e lugar seja prontamente utilizado. Mas, o homem, que está dentro de uma situação particular, não pode tomar decisões com base apenas em seu conhecimento dos fatos relativos aos seus arredores imediatos, pois, apesar de este ser um conhecimento íntimo, é também limitado.

No entanto, persiste o problema de como transmitir a esse homem informações suficientes para que ele seja capaz de encaixar suas decisões no padrão geral das mudanças do sistema econômico como um todo. Ou seja, se trata, então, de revelar o quanto de conhecimento ele precisa para ser bem sucedido nisso? Quais dos eventos que acontecerão além do seu horizonte imediato de conhecimento são relevantes para sua decisão imediata, e quão bem ele precisa conhecer esses eventos?

Praticamente não há nada que ocorra no mundo que não possa influenciar a decisão que ele precisa tomar. Mas ele não precisa conhecer esses eventos em si mesmos, nem precisa conhecer todos os seus efeitos. Para ele, não é importante saber o porquê de certo tipo de parafuso estar sendo mais procurado em uma época específica, ou por que os sacos de papéis estão mais facilmente disponíveis que os sacos de lona, ou por que trabalhadores especializados ou máquinas específicas momentaneamente se tornaram difíceis de encontrar.

Tudo que ele precisa saber é quão mais ou menos difícil está a aquisição de certas coisas em relação a outras coisas que também lhe interessam, ou se a demanda por outras coisas que ele produz ou usa é mais ou menos urgente. Ele sempre está preocupado com a importância relativa de coisas particulares, enquanto os fatores que alteram essa importância relativa 
não lhe interessam de forma alguma, exceto na medida dos próprios efeitos causados sobre as coisas concretas do seu ambiente.

É em relação a isso que aquilo que chamei de "cálculo econômico" nos ajuda, ao menos por analogia, a entender como esse problema pode ser resolvido - na verdade, como ele já está sendo resolvido - pelo sistema de preços. Mesmo se existisse uma única mente controladora que possuísse todos os dados sobre um sistema econômico pequeno e restrito, ela não iria dar-se ao trabalho de repassar por todas as relações entre fins e meios que talvez possam ser afetadas a cada vez que algum pequeno ajuste na alocação de recursos fosse feito.

De fato, uma das grandes contribuições da lógica pura da escolha é ter demonstrado conclusivamente que mesmo uma única mente onisciente só poderia resolver esse tipo de problema por meio da construção e da constante utilização de taxas de equivalência (ou "valores" ou "taxas marginais de substituição"), ou seja, por meio da atribuição de um índice numérico a cada tipo de recurso que, sem ser derivado de nenhuma propriedade dessa coisa em particular, ainda refletisse ou condensasse sua relevância na estrutura total dos meios e fins.

Para cada pequena mudança, ela teria que considerar apenas esses índices quantitativos (ou "valores"), no qual a informação relevante estaria concentrada e, ao ajustar as quantidades uma a uma, ela poderia reorganizar todos os elementos sem precisar retomar todo o quebra-cabeça desde o início nem precisar parar a cada etapa para analisar novamente todos os elementos e suas ramificações.

Basicamente, em um sistema no qual o conhecimento dos fatos relevantes está disperso entre várias pessoas, os preços podem servir para coordenar as diferentes ações de várias pessoas, do mesmo modo como os valores subjetivos ajudariam aquela mente onisciente a coordenar as diferentes partes do seu plano.

Vale a pena contemplar, por um instante, um exemplo muito simples e comum do sistema de preços em ação, para ver exatamente o que ele pode fazer. Suponha por um instante que, em algum lugar do mundo, uma nova oportunidade de usar alguma matéria prima surgiu - tomemos o estanho como exemplo - ou, então, que alguma das fontes de estanho tenha sido eliminada.

Para o nosso exemplo, não importa - e é muito significativo que isso não importe - qual dessas duas causas tenham aumentado a escassez de estanho. Tudo que os usuários de estanho precisam saber é que parte do estanho que eles costumavam consumir agora está sendo usado com mais proveito em outro lugar e, em decorrência disto, eles precisam ser mais econômicos em seu uso.

Não é preciso nem que boa parte deles saiba de onde essa demanda mais urgentemente surgiu, nem mesmo em prol de quê eles irão poupar esses recursos. Basta que alguns deles saibam diretamente da existência da nova demanda e transfiram recursos para ela, que algumas outras pessoas percebam o vazio que foi então criado e ajam para preenchê-lo com recursos de outras fontes e, então, o efeito irá rapidamente se espalhar por todo o sistema econômico, influenciando não apenas todos os usos do estanho, mas também os usos dos seus substitutos, e dos substitutos desses substitutos, assim como a oferta de todas as coisas feitas de estanho, e a dos seus 
substitutos dessas coisas, e assim por diante; e tudo isso ocorre sem que a grande maioria daqueles que realizam essas substituições saiba nada sobre a causa original dessas mudanças.

O todo age como se fosse um único mercado, mas isso não ocorre porque cada um dos seus membros pôde analisá-lo como um todo, mas sim porque os campos limitados da visão de cada um tinham alcance suficiente para que, através de inúmeros intermediários, a informação relevante fosse comunicada para todos.

O mero fato de que há um preço para cada bem — ou, melhor dizendo, que cada preço local está ligado, de certa forma, com o custo de transportá-lo para esse local, e assim por diante - traz a mesma solução que uma única mente dotada de todas as informações (embora ela seja apenas uma possibilidade imaginária) teria alcançado, ainda que essas informações, na verdade, estejam dispersas entre todas as pessoas envolvidas no processo.

\section{PARTE VI}

Precisamos entender o sistema de preços como um mecanismo de transmissão de informações para podermos entender sua verdadeira função uma função que ele cumpre evidentemente com menos perfeição, na medida em que os preços se tornam mais rígidos. Mas, mesmo quando preços tabelados se tornam extremamente rígidos, as forças que normalmente atuariam causando mudanças no preço permanecem agindo, exercendo uma influência considerável sobre as mudanças em outros aspectos dos contratos.

O principal aspecto desse sistema é a economia de conhecimento com que ele opera. Ou, em outros termos, o quão pouco os participantes individuais precisam saber para serem capazes de tomar as decisões corretas. De forma abreviada, por meio de certo tipo de símbolo, apenas a informação mais essencial é transmitida adiante, e apenas para aqueles que estão interessados nela.

Não seria apenas uma metáfora se disséssemos que o sistema de preços é tipo um caixa registrador, ou um sistema de telecomunicações que permite aos produtores individuais observar apenas o movimento de alguns fatores - do mesmo modo como um engenheiro pode se concentrar apenas nos consoles de alguns mostradores - para adaptar as suas atividades às mudanças que eles conhecem, apenas a partir do que é mostrado pelo movimento dos preços.

Evidentemente, esses ajustes provavelmente nunca são perfeitos, no sentido do modelo de perfeição que os economistas utilizam em suas análises sobre o equilíbrio econômico.

No entanto, temo que nosso hábito teórico de abordar cada problema com a presunção de um conhecimento mais ou menos perfeito, da parte de quase todos os envolvidos, quase nos tenha cegado para a verdadeira função do mecanismo de preço, levando-nos a aplicar de forma enganosa padrões inadequados para julgar sua eficiência.

É maravilhoso que em uma situação na qual haja escassez de um tipo de matéria prima, sem que nenhuma ordem seja dada, sem que talvez não mais que um punhado de pessoas saibam a causa dessa escassez, dezenas de milhares de pessoas, cujas identidades jamais serão conhecidas, mesmo depois de meses de investigação, comecem, então, a utilizar essa matéria ou 


\section{AKED置}

seus subprodutos de maneira mais econômica. Ou seja, todas elas agem na direção correta.

Isto, em si mesmo, é suficientemente maravilhoso, mesmo que, em um mundo de incertezas constantes, nem tudo consiga se organizar tão perfeitamente para que suas porcentagens de lucros se mantenham constantemente no mesmo nível considerado como "normal".

Usei deliberadamente a palavra "maravilha" para chocar o leitor e retirálo da complacência com que costumamos dar como certo o funcionamento desse mecanismo. Estou convencido de que se isso fosse o resultado de um projeto humano consciente, e que as pessoas guiadas pelas mudanças dos preços soubessem que suas decisões possuem uma importância muito maior do que a realização dos seus fins imediatos, então esse mecanismo seria louvado como um dos maiores triunfos da mente humana.

O seu azar é duplo: nem ele é o fruto de um projeto humano, nem as pessoas guiadas por ele costumam entender por que elas fazem as coisas que são levadas a fazer. Mas, aqueles que clamam por uma "direção consciente" - e que não podem acreditar que algo que tenha sido criado sem um planejamento (e, de fato, sem que nem mesmo alguém o compreendesse como um todo) possa resolver problemas que nós mesmos não podemos resolver conscientemente - devem lembrar-se do seguinte: o problema é precisamente o de como expandir a extensão da utilização dos recursos além da extensão do entendimento de um único indivíduo. $\mathrm{E}$, portanto, trata-se agora de um problema de como administrar a necessidade de controle consciente, e de como dar incentivos para os indivíduos tomarem as decisões desejáveis, sem que alguém lhes diga o que fazer.

O problema de que estamos tratando aqui, de forma alguma diz respeito exclusivamente à Economia, pois ele surge junto com quase todos os outros verdadeiros fenômenos sociais, com a linguagem e boa parte da nossa herança cultural, constituindo, de fato, o problema central de toda a Ciência Social. Como Alfred Whitehead ${ }^{2}$ disse, em relação à outra coisa:

Um truísmo profundamente falso, repetido por todos os manuais e nos discursos das pessoas eminentes, diz que devemos cultivar o hábito de pensar sobre o que estamos fazendo. O oposto é que é verdadeiro. A civilização progride quando aumentamos o número de trabalhos importantes que podemos realizar sem pensar neles ${ }^{3}$.

Isso possui uma profunda importância no campo social. Usamos constantemente fórmulas, símbolos e regras cujo significado não entendemos, mas, por meio dos quais, podemos ter acesso a conhecimentos que, individualmente, não possuímos. Criamos essas práticas e instituições tomando como base os hábitos e instituições que se mostraram bem sucedidos em suas próprias esferas e que se tornaram a fundação em cima da qual construímos a civilização.

\footnotetext{
${ }^{2}$ Alfred North Whitehead (1861-1947) foi um filósofo, lógico e matemático britânico. É o fundador da Escola filosófica conhecida como a Filosofia do Processo, atualmente aplicada em vários campos da ciência, como dentre outros na Ecologia, Teologia, Pedagogia, Física, Biologia, Economia e Psicologia (Nota editorial da Revista AKEDIA, 2021).

3 Não foi possível na editoração saber exatamente em qual obra da ampla produção literária de Whitehead, Hayek encontrou esta citação.
} 
O sistema de preços é apenas uma dessas criações que o homem aprendeu a usar (embora ele ainda esteja longe de ter aprendido a usá-lo perfeitamente), depois que se deparou com ele, mesmo antes de entendê-lo. Por meio dele, então, não apenas a divisão de trabalho, mas também o uso coordenado de recursos baseado em conhecimentos amplamente divulgados se tornam possíveis.

As pessoas que gostam de ridicularizar qualquer sugestão de que é assim que as coisas funcionam, distorcem nosso argumento, ao insinuar que estamos dizendo que é por algum milagre que um sistema como esse se desenvolveu espontaneamente, tornando-se 0 mais adequado para a civilização moderna. Trata-se exatamente do contrário: o homem pode criar essa divisão do trabalho sobre a qual a nossa civilização se sustenta, justamente porque ele se deparou com um método que a tornou possível.

Caso isso não tivesse ocorrido, ele talvez tivesse desenvolvido um tipo inteiramente diferente de civilização, talvez o "Estado" dos cupins, ou outra coisa totalmente inimaginável. Tudo que podemos dizer é que até agora ninguém conseguiu produzir um sistema alternativo em que certas características do sistema existente - que são respeitadas mesmo por aqueles que 0 atacam violentamente - possam ser preservadas, especialmente em relação à capacidade do indivíduo de escolher seus objetivos e, consequentemente, de dispor livremente de suas habilidades e conhecimento.

\section{PARTE VII}

Por vários motivos, é ótimo que a necessidade do sistema de preços, para qualquer cálculo racional em uma sociedade complexa, já não seja mais objeto de discussão apenas entre grupos com opiniões políticas distintas. A tese, segundo a qual sem o sistema de preços nós não poderíamos preservar uma sociedade baseada numa divisão de trabalho tão extensiva quanto a nossa, foi recebida com gritos de chacota, quando Mises ${ }^{4}$ a apresentou, há vinte e cinco anos.

Hoje, os argumentos que alguns ainda apresentam para rejeitar essa tese, não são mais exclusivamente políticos, e isso cria uma atmosfera muito mais receptível a discussões ponderadas. Quando vemos Leon Trostky ${ }^{5}$ argumentando que o "cálculo econômico é inimaginável sem as relações de mercado"6, ou quando o professor Oskar Lange ${ }^{7}$ promete ao professor von Mises uma estátua de mármore no futuro Diretório de Planejamento Central, e

\footnotetext{
${ }^{4}$ Ludwig Heinrich Edler von Mises (1881-1973) foi um economista teórico, de nacionalidade austríaca e, posteriormente, americana, que foi membro da Escola Austríaca de pensamento econômico. É conhecido principalmente por seu trabalho no campo da Praxeologia, o estudo dedutivo das ações e escolhas humanas (Nota editorial da Revista AKEDIA, 2021).

${ }^{5}$ Leon Trótski (1879-1940) foi um intelectual marxista e revolucionário bolchevique, organizador do Exército Vermelho e, após a morte de Lenin, rival de Stalin na disputa pela hegemonia do Partido Comunista da União Soviética, tornou-se figura central da vitória bolchevique na Guerra Civil Russa (Nota editorial da Revista AKEDIA, 2021).

${ }^{6}$ Não foi possível na editoração saber exatamente em qual obra da ampla produção literária de Leon Trostky, Hayek encontrou esta citação.

${ }^{7}$ Oskar Ryszard Lange (1904-1965) foi um economista e diplomata polonês. Suas ideias, opostas às de Ludwig von Mises, fizeram com que analisasse os preceitos econômicos da Escola Austríaca (Nota editorial da Revista AKEDIA, 2021).
} 


\section{AKEDIA}

quando o professor Abba P. Lerner ${ }^{8}$ redescobre Adam Smith ${ }^{9}$, enfatizando que a utilidade essencial do sistema de preços consiste em induzir o indivíduo a fazer aquilo que é do interesse geral, no instante em que busca realizar seus próprios interesses. Daí, então, as divergências já não podem ser atribuídas somente a preconceitos políticos.

Os dissidentes restantes parecem claramente divergir dessa posição, movidos por motivos puramente intelectuais e, mais particularmente, por causa de diferenças metodológicas.

Uma declaração recente do professor Joseph Schumpeter ${ }^{10}$, em seu "Capitalismo, socialismo e democracia", fornece um exemplo perfeito dessas diferenças metodológicas que tenho em mente. $\mathrm{O}$ autor é um dos economistas mais proeminentes entre aqueles que analisam o fenômeno econômico a partir de algum ramo do Positivismo.

Para ele, esses fenômenos surgem por consequência do mútuo efeito exercido por certas quantidades objetivas de bens, quase como se não houvesse intervenção alguma de mentes humanas. Apenas por causa desses pressupostos, posso compreender a declaração seguinte - e, para mim, espantosa.

O professor Schumpeter argumenta que a possibilidade do cálculo racional na ausência de um mercado para os fatores de produção é uma decorrência da proposição teórica, segundo a qual "os consumidores que estão avaliando (demandando) os bens de consumo ipso facto também estão avaliando os meios de produção que entram na produção daqueles bens".

Assim, me parece que Schumpeter é o responsável pela criação do mito, segundo o qual Pareto e Barone ${ }^{11}$ teriam "resolvido" o problema do cálculo econômico no Socialismo. O que eles e muitos outros fizeram, no entanto, foi apenas elencar as condições que deveriam ser satisfeitas para uma alocação racional de recursos, e observar que essas condições eram essencialmente as mesmas do estado de equilíbrio de um mercado competitivo.

Isso é inteiramente diferente de saber como a alocação de recursos, segundo essas condições, pode ser observada na prática. O próprio Pareto (de quem Barone praticamente tomou quase tudo o que tinha a dizer), longe de declarar ter "resolvido" esse problema prático, de fato, negou explicitamente que ele poderia ser solucionado sem o auxílio do mercado. Vejam, sobre isso, o seu Manual de Economia Pura (1927, p. 233-234). Por sinal, as passagens relevantes do texto estão citadas em uma tradução inglesa, no início do meu artigo "O cálculo socialista: a 'solução' competitiva" (In: Economica. New Series, vol. VIII, n. 26, may, 1940, p. 125.

\footnotetext{
${ }^{8}$ Abraham "Abba" Ptachya Lerner (1903-1982) foi um economista britânico nascido na Rússia, na Bessarábia. Cresceu em uma família judia e emigrou para a Grã-Bretanha, quando Lerner tinha três anos (Nota editorial da Revista AKEDIA, 2021).

${ }^{9}$ Adam Smith (1723-1790) filósofo e economista britânico, nascido na Escócia. Teve como cenário de vida o atribulado "Século das Luzes" - XVIII. É tido como o pai da economia moderna, e é considerado o mais importante teórico do liberalismo econômico (Nota editorial da Revista AKEDIA, 2021).

${ }^{10}$ Joseph Alois Schumpeter (1883-1950) foi um economista e cientista político austríaco. É considerado um dos mais importantes economistas da primeira metade do século $\mathrm{XX}$, e foi um dos primeiros a considerar as inovações tecnológicas como sendo o motor do desenvolvimento capitalista (Nota editorial da Revista AKEDIA, 2021).

${ }^{11}$ Enrico Barone (1859-1924) foi um soldado romano, historiador militar e economista. A partir de 1894, ele colaborou com no Giornale degli Economisti, com Maffeo Pantaleoni e, Vilfredo Pareto (1848-1923), cientista político, sociólogo e economista italiano (Nota editorial da Revista AKEDIA, 2021).
} 
Tomada literalmente, essa declaração de Schumpeter é simplesmente falsa. Os consumidores não fazem nada disso. O que o "ipso facto" do professor Schumpeter provavelmente significa é que a avaliação dos fatores de produção está implícita, ou que se segue necessariamente, da avaliação dos bens de consumo. Mas isso também não é verdadeiro.

A implicação é uma relação lógica que só pode ser afirmada com segurança, a partir de pressupostos que estejam para o mesmo indivíduo. É evidente, no entanto, que os valores dos fatores de produção não dependem exclusivamente da avaliação dos bens de consumo, mas, também, das condições de fornecimento dos vários fatores de produção.

Apenas um único indivíduo que conhecesse todos esses fatores simultaneamente poderia encontrar uma resposta derivada diretamente desses dados. O problema prático surge, no entanto, precisamente porque esses dados nunca estão inteiramente disponíveis para um único indivíduo, e porque, por consequência, é necessária para resolver esse problema a utilização de conhecimentos que estão dispersos por vários indivíduos.

O problema, portanto, não estaria de forma alguma resolvido, se demonstrássemos que todos os dados, se estivessem disponíveis para uma única mente (como hipoteticamente estariam para 0 economista que observasse o problema), iriam por si mesmos determinar a solução. Ao invés disso, precisaríamos demonstrar como uma solução poderia ser produzida pela interação entre as pessoas que, individualmente, possuem apenas um conhecimento parcial. Presumir que todo o conhecimento possa ser colocado à disposição de uma única mente, do modo como presumimos que ele pode estar disponível para nós, como economistas dedicados a analisar uma questão, equivale a fugir do problema e menosprezar tudo que é importante e relevante no mundo real.

Que um economista, da estatura do professor Schumpeter, tenha caído em tal armadilha, por causa da ambiguidade que o termo "dado" tem para os incautos, dificilmente poderia ser considerado um simples erro. Isto sugere, de fato, que há algo de fundamentalmente errado com uma abordagem que frequentemente despreza uma parte essencial dos fenômenos com os quais temos que lidar: a inevitável imperfeição do conhecimento humano e a necessidade decorrente de um processo, por meio do qual o conhecimento seja constantemente adquirido e transmitido.

Qualquer abordagem - como grande parte da economia matemática, com suas várias equações simultâneas - que parta do pressuposto de que 0 conhecimento das pessoas corresponde aos fatos objetivos, irá sistematicamente deixar de lado aquilo que é a nossa principal tarefa explicar.

Estou longe de negar que, em nosso sistema, a análise do equilíbrio econômico tem uma atividade útil a desempenhar, mas quando chega o ponto em que ela ofusca nossos principais intelectuais, fazendo-os acreditar que a situação que estão descrevendo tem uma relevância direta para a solução de problemas práticos, está mais que na hora de nos lembrarmos de que esse tipo de análise não lida com o processo social de forma alguma, e de que isso não é mais do que uma etapa preliminar para a investigação do problema principal. 